\title{
Motivated strategies for learning and their association with academic performance of a diverse group of 1 st-year medical students
}

\author{
S Hamid, BSocSc, BSocSc Hons, MA, PhD; V S Singaram, BMedSc, MMedSc, PhD \\ Clinical and Professional Practice, School of Clinical Medicine, College of Health Sciences, University of KwaZulu-Natal, Durban, South Africa
}

Corresponding author: S Hamid (shaista.saib@gmail.com)

Background. Most instruments, including the well-known Motivated Strategies for Learning Questionnaire (MSLQ), have been designed in western homogeneous settings. Use of the MSLQ in health professions education is limited.

Objective. To assess the MSLQ and its association with the academic performance of a heterogeneous group of 1st-year medical students.

Methods. Eighty-three percent of 1st-year medical students consented to participate in this quantitative study. The MSLQ consisted of a motivation strategies component with six subscales, while the learning strategies component had nine subscales. Demographic and academic achievement information of the students was also collected. Stata version 13 (StataCorp LP, USA) was used for the statistical analyses of all data.

Results. Female students displayed significantly higher motivational scores. Students with prior educational experience and those who attended peermentoring sessions had significantly higher learning strategy scores. Significant but moderate relationships were found between academic performance and the motivation strategies subsumed within the categories 'task value' and 'self-efficacy for learning performance'. In terms of the 'learning strategy component', 'critical thinking', and 'time and study environment', the composite score was significantly but poorly correlated to academic performance.

Conclusion. Overall, limited correlations were found between the MSLQ scores and academic performance. Further investigation of the use of the MSLQ and its association with academic achievement is recommended, with greater focus on specific learning events than on course outcomes. This study highlights the importance of evaluating an instrument in a specific context before accepting the findings of others with regard to the use of the instrument and its correlation with academic performance.

Afr J Health Professions Educ 2016;8(1 Suppl 1):104-107. DOI:10.7196/AJHPE.2016.v8i1.757

Poor learning strategies are among the factors responsible for the high failure rate of 1st-year students. ${ }^{[1]}$ Non-cognitive factors must be taken into account to facilitate academic success. ${ }^{[2]}$ Motivation is a prominent factor, which is linked to positive academic outcomes and associated with psychological wellbeing. ${ }^{[3]}$ Motivation is one of the central constructs in understanding academic performance and influencing learning strategies. Students with higher motivation levels are more attentive and engaged in their learning than those with lower levels of motivation. ${ }^{[4]}$ The former may be viewed as self-regulated students with a higher degree of independent engagement in their learning processes. Self-regulation has been defined as the 'mindful capacity to plan, guide and monitor one's behaviour flexibly according to changing circumstances and is considered as vital for autonomous and adaptive functioning' ${ }^{[5]}$ Therefore, self-regulated learners tend to be cognitively, emotionally and behaviourally involved in their learning processes. ${ }^{[6]}$

Among medical students, high motivation was linked to high academic performance in both the preclinical and clinical years and to health-related extracurricular activities. ${ }^{[7]}$ Although these results are supported by other studies, ${ }^{[8-10]}$ contradictory findings, related to lack of association between academic performance and motivation, have also been published. ${ }^{[11]}$ Lack of motivation or amotivation has also been found to be one of the important barriers to learner achievement and performance. ${ }^{[12]}$ Therefore, factors that enhance motivation need to be investigated. Motivation is understood to be triggered by intrinsic or extrinsic factors. Intrinsic motivation refers to a person's actions being influenced by an internal state - a self-determined form of motivation. ${ }^{[13]}$ External motivation, in contrast, is influenced by external sources, e.g. an anticipated reward. Both intrinsic and extrinsic forms of motivation have been found to be positively associated with adjustment to university. ${ }^{[13]}$ Consequently, students who are well adjusted experienced a sense of belonging within the university, did not feel overwhelmed by the amount of work, and performed well academically. ${ }^{[7]}$

Much research on motivation has been done in general education, but in medical education such research has been limited. ${ }^{[7]}$ While there are many instruments to measure motivation and learning strategies, most of these, including the well-known Motivated Strategies for Learning Questionnaire (MSLQ), ${ }^{[14]}$ have been designed in settings in western countries. Use of the MSLQ in health professions education is also limited. Hence, the objective of this study was to assess the MSLQ and its association with the academic performance of a diverse group of 1st-year medical students.

\section{Methods}

All 1st-year medical students at the Nelson R Mandela School of Medicine (NRMSM), University of KwaZulu-Natal (UKZN), Durban, South Africa were invited to participate. A total of 200 questionnaires were distributed; 165 students $(83 \%)$ consented to completing the questionnaire. The summative end of semester academic results of the only two compulsory academic modules involving all 1st-year students (Becoming a Professional and Basic Science) were obtained from the Faculty of Medicine. Ethics approval and gatekeeper permission were obtained from UKZN's Human Social Sciences Research Ethics Committee (HSS/0119/013D).

\section{Instrument}

The research instrument contained 95 items, with nominal and ordinal levels of measurement. It comprised two sections, i.e. a demographic section and the MSLQ. ${ }^{[7]}$ The demographic section consisted of 14 items related to gender, age, type of school (urban v. rural), attendance of peer-mentoring 
sessions, attendance of study skills sessions and degree choice. The MSLQ had 81 items. ${ }^{[14]}$ This validated scale assesses motivation and self-regulated learning strategies, as illustrated in Table 1.

\section{Data analysis}

Stata version 13 (StataCorp LP, USA) was used for analysis of all the data. ${ }^{[15]}$ Reliability was measured using Cronbach's $\alpha$, which determines the internal consistency or average correlation of items in a survey instrument to gauge its internal validity. Continuous variables were first inspected using the ShapiroWilk and Shapiro-Francia tests for normality to determine which statistical tests were appropriate for the data. The data that were found to be normally distributed were analysed using parametric tests. Non-parametric tests were employed for data that were not normally distributed. For normally distributed data, the two independent samples $t$-test was used to compare mean composite scores for two independent groups. A one-way analysis of variance (ANOVA) was used for categorical independent variables (three or more categories) and a normally distributed interval-dependent variable (composite scores of learning strategy) to test for differences in the means of the dependent variable broken down by the levels of the independent variable. Otherwise, non-parametric equivalent tests were used. With regard to scoring of the MSLQ, students rated themselves on a 7-point Likert scale from 1 (not at all true of me) to 7 (very true of me). Scales were constructed by taking the mean of the items that comprise that scale, e.g. intrinsic goal orientation (IGO) has four items. An individual's score for IGO was computed by adding the four items and dividing the total by the number of items to obtain an average score.

\section{Results}

Table 1 depicts the reliability and descriptive statistics obtained for the MSLQ. The reliability statistics for the MSLQ displayed fair to good internal validity.

\begin{tabular}{lll}
\multicolumn{4}{l}{ Table 1. Reliability and descriptive statistics for the MSLQ $(\mathbf{N}=\mathbf{1 6 5})$} \\
\hline MSLQ scales & Mean (SD) & Cronbach's $\alpha$ \\
\hline Motivation strategies & & \\
Intrinsic goal orientation (4 items ) & $5.01(1.07)$ & 0.60 \\
Extrinsic goal orientation (4 items) & $5.75(1.04)$ & 0.62 \\
Task value (6 items) & $5.71(0.97)$ & 0.80 \\
Control of learning beliefs (4 items) & $5.44(1.03)$ & 0.51 \\
Self-efficacy for learning and & $5.22(1.04)$ & 0.88 \\
performance (8 items) & & \\
Test anxiety (5 items) & $4.42(1.32)$ & 0.68 \\
Learning strategies & & \\
Rehearsal (4 items) & $5.01(1.22)$ & 0.64 \\
Elaboration (6 items) & $5.12(1.14)$ & 0.80 \\
Organisation (4 items) & $5.16(1.28)$ & 0.71 \\
Peer learning (3 items) & $3.98(1.61)$ & 0.72 \\
Critical thinking (5 items) & $4.26(1.30)$ & 0.77 \\
Metacognitive self-regulation (12 items) & $4.67(0.97)$ & 0.77 \\
Time and study environment (8 items) & $4.53(0.96)$ & 0.55 \\
Effort regulation (4 items) & $4.97(1.27)$ & 0.58 \\
Help-seeking (4 items) & $3.87(1.27)$ & 0.56 \\
SD = standard deviation. & & \\
& & \\
\hline
\end{tabular}

Most of the sections have a reliability score that is close to or exceeds the recommended value of 0.7 . This indicates an overall degree of acceptable, consistent scoring of items within each construct.

\section{Analyses of relationship between demographic characteristics, academic performance and motivation}

As illustrated in Table 2, statistically significant differences were found between male and female students in the composite score for motivation $(p=0.03)$. Based on the rank sum (7 814) and expected rank sum (8 466) scores, female students had much higher scores than males. No other statistically significant relationships were found between student characteristics and motivation.

Task value, self-efficacy for learning performance and test anxiety (inversely) correlated significantly with both modules (Table 3). IGO and control of learning beliefs correlated significantly but poorly with the Becoming a Professional module. The composite score for motivation and other subscales had limited correlation with the academic performance in both modules.

Table 2. Comparison between composite score for motivation and demographics: Mann-Whitney $U$-test $(N=165)^{*}$

\begin{tabular}{|c|c|c|c|c|c|}
\hline \multirow[b]{2}{*}{$\begin{array}{l}\text { Student } \\
\text { characteristics }\end{array}$} & \multicolumn{5}{|c|}{ Test statistics } \\
\hline & $n$ & $\begin{array}{l}\text { Rank } \\
\text { sum }\end{array}$ & $\begin{array}{l}\text { Expected } \\
\text { rank sum }\end{array}$ & $z$-score & $p$-value \\
\hline \multicolumn{6}{|l|}{ Gender } \\
\hline Male & 63 & 5881 & 5229 & 2.190 & 0.03 \\
\hline Female & 103 & 7814 & 8466 & & \\
\hline \multicolumn{6}{|c|}{$\begin{array}{l}\text { Geographical area } \\
\text { of high school }\end{array}$} \\
\hline Urban & 92 & 7481 & 7636 & -0.509 & 0.61 \\
\hline Rural & 73 & 6214 & 6059 & & \\
\hline \multicolumn{6}{|c|}{$\begin{array}{l}\text { Medical degree first } \\
\text { or second choice }\end{array}$} \\
\hline First & 142 & 11710 & 11786 & 0.358 & 0.72 \\
\hline Second & 23 & 1985 & 1909 & & \\
\hline \multicolumn{6}{|c|}{$\begin{array}{l}\text { Satisfied with the } \\
\text { current degree } \\
\text { choice }\end{array}$} \\
\hline Yes & 159 & 13210.5 & 13117.5 & 0.891 & 0.37 \\
\hline No & 5 & 319.5 & 412.5 & & \\
\hline \multicolumn{6}{|l|}{$\begin{array}{l}\text { Student has a } \\
\text { previous degree }\end{array}$} \\
\hline Yes & 21 & 1944.5 & 1732.5 & 1.045 & 0.3 \\
\hline No & 143 & 11585.5 & 11797.5 & & \\
\hline \multicolumn{6}{|l|}{$\begin{array}{l}\text { Attended study } \\
\text { skills sessions }\end{array}$} \\
\hline Yes & 36 & 2959 & 2970 & -0.044 & 0.97 \\
\hline No & 128 & 10571 & 10560 & & \\
\hline \multicolumn{6}{|c|}{$\begin{array}{l}\text { Attended peer- } \\
\text { mentoring sessions }\end{array}$} \\
\hline Yes & 135 & 11551 & 11205 & 1.464 & 0.14 \\
\hline No & 30 & 2144 & 2490 & & \\
\hline
\end{tabular}




\section{Correlational analyses of learning strategies}

Independent sample $t$-test results in Table 4 depict that having obtained a previous degree and attending peer-mentoring sessions were found to be statistically significantly correlated with the learning strategies adopted. No significant associations were found between learning strategies and other demographic variables or student characteristics.

The time and study environment subscale was moderately significantly correlated with both academic modules (Table 5). The composite score for the learning strategies and the rest of the eight subscales significantly correlated poorly with academic performance in both academic modules.

\section{Discussion}

This study explored the motivated strategies for learning and their association with the academic performances of a diverse group of 1st-year medical students. The MSLQ instrument was found to be reliable, as there was an overall degree of acceptable, consistent scoring of items within the different categories. Statistically significant differences were found between gender and the composite score for motivation. Similar to Sikhwari's ${ }^{[16]}$ results, it was found that females had higher scores then males. These studies revealed that females generally engage more with academic activities than males and are consequently higher achievers academically. By comparison, men are reported to place less value on engaging with academic activities.

Although urban students had higher scores than their rural counterparts, the differences, such as those between the other characteristics and demographic factors, were not significant. Significant moderate relationships were found between academic performance and the motivation strategies subsumed within task value and self-efficacy for learning performance. Task value refers to students' perceptions of how important they believe the subject matter is. It is also associated with higher engagement in learning. These students may be more likely to put in greater effort if they appraise academic content as meaningful and relevant. Increased effort and engagement with the subject matter could contribute positively to academic performance. Self-efficacy for learning performance relates to the students' sense of confidence in their ability to achieve their goals. The influence of self-efficacy on motivation is often ignored

Table 3. Correlations between six subscales of motivation and academic performance with regard to two modules in 1st year of medical school

\begin{tabular}{|c|c|c|}
\hline & $\begin{array}{l}\text { Becoming a } \\
\text { Professional }(n=158)\end{array}$ & $\begin{array}{l}\text { Basic Science } \\
(n=152)\end{array}$ \\
\hline Subscales & $r^{*}$ & $r^{*}$ \\
\hline Intrinsic goal orientation (average subscore) & $0.1864^{\dagger}$ & 0.13 \\
\hline Extrinsic goal orientation (average subscore) & -0.0016 & -0.07 \\
\hline Task value (average subscore) & $0.2533^{\dagger}$ & $0.19^{\dagger}$ \\
\hline Control of learning beliefs (average subscore) & $0.1777^{\dagger}$ & 0.13 \\
\hline Self-efficacy for learning performance (average subscore) & $0.3672^{\dagger}$ & $0.27^{\S}$ \\
\hline Test anxiety (average subscore) & $-0.3379^{\S}$ & $-0.21^{*}$ \\
\hline $\begin{array}{l}\text { Composite score for motivation } \\
\text { (combining the above average subscores) }\end{array}$ & 0.1382 & 0.09 \\
\hline $\begin{array}{l}{ }^{*} \text { Pearson's product moment correlation coefficient. } \\
\text { "Correlation at } p<0.05 \text { (two-tailed). } \\
\text { "Correlation at } p<0.01 \text { (two-tailed). } \\
{ }^{\text {\& }} \text { Correlation at } p<0.001 \text { (two-tailed). }\end{array}$ & & \\
\hline
\end{tabular}

Table 4. Comparison of students' characteristics by their mean composite scores for learning strategy - independent sample $t$-test $(N=165)^{*}$

\begin{tabular}{|c|c|c|c|c|}
\hline \multirow[b]{2}{*}{ Student characteristics } & \multicolumn{4}{|c|}{ Test statistics } \\
\hline & $n$ & Mean (SD) & 95\% CI & $p$-value \\
\hline \multicolumn{5}{|l|}{ Gender } \\
\hline Male & 63 & $4.85(0.76)$ & $4.66-5.05$ & 0.11 \\
\hline Female & 101 & $4.65(0.81)$ & $4.49-4.81$ & \\
\hline \multicolumn{5}{|c|}{ Geographical area where high school was completed } \\
\hline Urban & 92 & $4.67(0.83)$ & $4.49-4.84$ & 0.25 \\
\hline Rural & 72 & $4.81(0.75)$ & $4.63-4.98$ & \\
\hline \multicolumn{5}{|c|}{ Medical degree first or second choice } \\
\hline First & 141 & $4.75(0.76)$ & $4.62-5.07$ & 5.07 \\
\hline Second & 23 & $4.63(0.99)$ & 4.21 & \\
\hline \multicolumn{5}{|c|}{ Satisfied with the current degree choice } \\
\hline Yes & 158 & $4.75(0.78)$ & $4.62-4.88$ & 0.11 \\
\hline No & 5 & $4.18(0.98)$ & $2.96-5.39$ & \\
\hline \multicolumn{5}{|l|}{ Previous degree } \\
\hline Yes & 21 & $5.05(0.94)$ & $4.63-5.46$ & 0.05 \\
\hline No & 142 & $4.73(0.79)$ & $4.61-4.81$ & \\
\hline \multicolumn{5}{|c|}{ Attended study skills sessions } \\
\hline Yes & 36 & $4.76(0.73)$ & $4.51-5.01$ & 0.82 \\
\hline No & 127 & $0.79(0.79)$ & $4.61-4.85$ & \\
\hline \multicolumn{5}{|c|}{ Attended mentoring sessions } \\
\hline Yes & 135 & $4.80(0.82)$ & $4.66-4.94$ & 0.01 \\
\hline No & 29 & $4.41(0.79)$ & $4.61-4.85$ & \\
\hline
\end{tabular}

in research; yet students' beliefs in their own ability are important and merit attention. ${ }^{[17]}$ Self-efficacy and academic performance are interlinked and can be mutually beneficial, as was found previously. ${ }^{[17]}$ Conversely, unlike results of other studies, ${ }^{[18]}$ intrinsic and extrinsic goal orientation correlated poorly with one academic performance in this study. 
Table 5. Correlations between nine subscales of the learning strategy scale and academic performance with regard to two modules in 1 st year of medical school $(n=157)$

\begin{tabular}{|c|c|c|}
\hline Subscales & $\begin{array}{l}\text { Becoming a } \\
\text { Professional } \\
r^{\star}\end{array}$ & $\begin{array}{l}\text { Basic } \\
\text { Science } \\
r^{*}\end{array}$ \\
\hline Rehearsal (average subscore) & 0.0397 & -0.01 \\
\hline Elaboration (average subscore) & 0.1407 & 0.09 \\
\hline Organisation (average subscore) & 0.0766 & 0.01 \\
\hline Peer learning (average subscore) & 0.0753 & 0.01 \\
\hline Critical thinking (average subscore) & $0.1862^{\dagger}$ & $0.16^{\dagger}$ \\
\hline Metacognitive self-regulation (average subscore) & $0.2082^{\ddagger}$ & 0.09 \\
\hline Time and study environment (average subscore) & $0.3041^{\varsigma}$ & $0.25^{\ddagger}$ \\
\hline Effort regulation (average subscore) & $0.2098^{\ddagger}$ & 0.10 \\
\hline Help seeking (average subscore) & 0.0658 & 0.01 \\
\hline $\begin{array}{l}\text { Composite score for learning strategy (combining } \\
\text { the above average subscores) }\end{array}$ & $0.2125^{\ddagger}$ & 0.11 \\
\hline $\begin{array}{l}\text { *Pearson's product moment correlation coefficient. } \\
{ }^{*} \text { Correlation at } p<0.05 \text { (two-tailed). } \\
\text { "Correlation at } p<0.01 \text { (two-tailed) } \\
\text { "Correlation at } p<0.001 \text { (two-tailed). }\end{array}$ & & \\
\hline
\end{tabular}

In our study, test anxiety was found to have a significantly inverse relationship to academic performance. Opatey $\mathrm{e}^{[8]}$ also found a significant negative relationship between test anxiety and academic performance. The results of this article suggest that students with high task value and high self-efficacy may present with lower test anxiety, as they may be more likely to feel better equipped to deal with the examinations and would probably judge themselves as prepared for the task at hand. Performing well academically further reinforces these feelings and motivation, which may become a cyclical process of continued engagement and motivation. This is supported by previous studies on self-efficacy and its relationship with test anxiety. ${ }^{[9,10]}$ However, our study found that the majority of the six subscales of motivation and academic performance were poorly correlated, although some significant associations were noted.

In the 'learning strategies' section, students who had prior higher education qualifications obtained higher scores than those who entered medical school without post-school qualifications. Students with existing qualifications are referred to as mature students and their higher scores may be due to their increased tertiary experience. Students who attended mentoring sessions also had significantly higher scores for learning strategies. This is a positive finding, as attending mentoring sessions is currently compulsory at NRMSM. This could act as a source of continuous external motivation and engagement with the learning process in a supportive context. This finding highlights the importance of peer-mentorship programmes for developing the student on a personal and academic level, as reported in other studies. ${ }^{[14]}$ With regard to the learning strategies, only the 'time and study environment' subscale showed some significant moderate correlation with academic performance. The significant though weak correlation between critical thinking and academic performance is contrary to findings in other studies, as critical thinking is expected to be positively associated with academic performance. This factor is indicative of deeper engagement with the academic content compared with rote learning. ${ }^{[18]}$ Overall, this study found limited correlations between the majority of the nine subscales of the learning strategy component of the MSLQ and academic performance.

A limitation of the study may be the correlation of once-off self-reported scores to end-of-year summative results. Future studies should perhaps be more focused by correlating the MSLQ to specific learning events. Additionally, several measurements throughout the year may address the possible bias attributed to self-reporting in studies investigating course or curriculum achievement outcomes.

\section{Conclusion}

Female students reported more positively on motivation strategies than males. First-year medical students with prior educational experience and those who attended the peer-mentoring sessions reported more positively on learning strategies that they adopted. This study found limited though significant correlations between the MSLQ self-reported scores and academic performance at UKZN. Overall, the study highlights the importance of evaluating an instrument in a specific context before accepting the findings of others with regard to the use of the instrument and its correlation with academic performance. These findings warrant further investigation of the use of the MSLQ in health professions education.

Acknowledgements. This publication was made possible by grant No. R24TW008863 from the Office of the US Global AIDS Coordinator and the US Department of Health and Human Services, National Institutes of Health (NIH OAR and NIH ORWH). Its contents are solely the responsibility of the authors and do not necessarily represent the official views of the US government. We thank the medical students for their participation in the study and Dr M Muzigaba for statistical guidance and analysis.

\section{References}

1. Maree CM, van Rensburg GH. Reflective learning in higher education: Application to clinical nursing. Afr J Phy Health Educ Recreation Dance 2013;19:44-55. [http://dx.doi.org/10.hdl.handle.net/2263/32417]

2. Munteanu A, Costea J, Palos R. Relationships between academic achievement and personality dynamics during adolescence. S Afr J Psychol 2011;41(4):552-561. [http://dx.doi.org/10.1177/008124631104100413]

3. Pajares P. Toward a positive psychology of academic motivation. J Educ Res 2001;95(1):27-35. [http://dx.doi org/10.1080/00220670109598780]

4. Schunk DH, Meece JL, Pintrich PR. Motivation in Education: Theory, Research and Applications. 4th ed. Boston Pearson, 2014

5. Wissing MP, ed. Well-Being Research in South Africa. New York: Springer, 2013.

6. Artino AR, Hemmer PA, Durning SJ. Using self-regulated learning theory to understand the beliefs, emotions, and behaviours of struggling medical students Acad Med 2011;86:S35-S38. [http://dx.doi.org/10.1097/ and behaviours of strugg in

ACM.0b013e31822a603d

7. Kusurkar RA, ten Cate THJ, van Asperen M, Croiset M. Motivation as an independent and a dependent variable in medical education: A review of the literature. Med Teach 2011;33:e242-e262. [http://dx.doi.org/10.3109/014 2159X.2011.558539]

8. Opateye JA. The relationship between emotional intelligence, test anxiety, stress, academic success and attitude of high school students towards electrochemistry. IFE Psychologia 2014;22(1):239-249.

9. Richardson M, Abraham C, Bond R. Psychological correlates of university students' academic performance: systematic review and meta-analysis. Psychol Bull 2012;138(2):353-387. [http://dx.doi.org/10.1037/a0026838]

10. Bertrams A, Englert C, Dickhauser O, Baumeister RF. Role of self-control strength in the relation between anxiety and cognitive performance. Emotion 2013;13(4):668-680. [http://dx.doi.org/10.1037/a0031921]

11. Petersen I, Louw L, Dumont K. Adjustment to university and academic performance among disadvantaged students in South Africa. Educ Psychol 2009;29(1):99-115. [http://dx.doi.org/10.1080/01443410802521066]

12. Students in South Africa. Educ Pychol 2009;29(1):99-115. [htp://dx.doi.org/ Getween studen

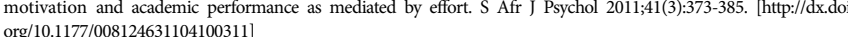

13. Sommer M, Dumont K. Psychosocial factors predicting academic performance of students at a historically disadvantaged university. S Afr J Psychol 2011;41(3):386-395. [http://dx.doi.org/10.1177/008124631104100312]

14. Pintrich PR, Smith DAF, Garcia T, McKeachie WJ. A Manual for the Use of the Motivated Strategies for Learning Questionnaire (MSLQ). Ann Arbor, Michigan: National Centre for Research to Improve Post-Secondary Teaching and Learning, 1991

15. StataCorp. Stata Statistical Software: Release 13. College Station, TX: StataCorp LP, 2013.

16. Sikhwari TD. A study of the relationship between motivation, self-concept and academic achievement of students at a university in Limpopo Province, South Africa. Int J Edu Sci 2014;6(1):19-25.

17. Javanmard A, Hoshmandja M, Ahmadzade L. Investigating the relationship between self-efficacy, cognitive and metacognitive strategies, and academic self-handicapping with academic achievement in male high schoo students in the tribes of Fars Province. J Life Sci Biomed 2013;3(1):27-34

18. Karbalaei A. Critical thinking and academic achievement. Medellin-Colombia 2012;17(2):121-128. 